\title{
Comitê de Auditoria e Gerenciamento de Resultados em Empresas Reguladas e Empresas Não Reguladas
}

\section{Audit Committees and Earnings Management in Regulated and Unregulated Public Firms}

\author{
David Stanhy de Carvalho Silva \\ Mestre em Administração e Controladoria pela Universidade Federal do Ceará (UFC) \\ Professor da Universidade Estadual do Piauí (UESPI), Campus Rio Marataoan \\ Rua Fenelon Castelo Branco, S/N, Centro, Barras-PI, CEP: 64.100-000 \\ E-mail: davidstanhy@gmail.com
}

\author{
Alessandra Carvalho de Vasconcelos \\ Doutora em Engenharia de Produção pela Universidade Federal de Santa Catarina (UFSC) \\ Professora da Universidade Federal do Ceará (UFC), Faculdade de Economia, Administração, \\ Atuária e Contabilidade (FEAAC) \\ Av. da Universidade, 2431, Benfica, Fortaleza-CE, CEP: 60.020-180 \\ E-mail: alevasconcelos.ufc@gmail.com
}

\author{
Márcia Martins Mendes De Luca \\ Doutora em Controladoria e Contabilidade pela Universidade de São Paulo (USP) \\ Professora da Universidade Federal do Ceará (UFC), Faculdade de Economia, Administração, \\ Atuária e Contabilidade (FEAAC) \\ Av. da Universidade, 2431, Benfica, Fortaleza-CE, CEP: 60.020-180 \\ E-mail: marciadeluca@ufc.br
}

\begin{abstract}
Resumo
Os diversos códigos de boas práticas de governança corporativa em todo o mundo recomendam a presença de órgãos técnicos, conhecidos como comitês, para assessorar o conselho de administração. Nesse contexto, destaca-se o comitê de auditoria, que deve ser constituído por membros independentes, com conhecimento na área, e tem, entre outras, a finalidade de inibir a prática de gerenciamento de resultados. O presente estudo analisa a correlação entre as características do comitê de auditoria e a prática de gerenciamento de resultados nas empresas listadas no IGCX, da BM\&FBovespa. As 66 empresas do IGCX com comitê de auditoria foram distribuídas em dois grupos, sendo 30 reguladas e 36 não reguladas, levando em conta que as empresas participantes de setores regulados por agências governamentais seguem normas e diretrizes que as diferenciam das demais. Analisaram-se os dados, utilizando-se o teste de diferença entre médias, o teste de correlação e o método de detecção de interação automática do qui-quadrado (Chaid). Os resultados indicam que não há diferenças entre as características dos comitês de auditoria das empresas reguladas e as dos comitês das não reguladas. Constatouse, ainda, que não há correlação entre as características dos comitês de auditoria e as práticas de gerenciamento de resultados nas empresas da amostra. Contudo, conclui-se, por meio da análise da árvore de segmentação, que as empresas de grande porte apresentam baixo nível de gerenciamento de resultados, são reguladas e possuem pequeno número de membros independentes no comitê de auditoria.
\end{abstract}

Palavras-chave: Comitê de auditoria. Gerenciamento de resultados. Empresas reguladas. Agências reguladoras.

Submetido em março de 2017 e aceito em setembro de 2017 pela editora Fernanda Sauerbronn, após processo de Double Blind Review

Artigo publicado anteriormente nos Anais do $2^{\circ}$ Congresso UnB de Contabilidade e Governança, realizado em Brasília, DF, em novembro de 2016. 


\begin{abstract}
Codes of good corporate governance practices around the world recommend the adoption of a number of technical committees to assist the board of directors. Among these, the audit committee is particularly important due to its role in the prevention of earnings management. To be effective, audit committees should ideally include independent outside directors and experts in the field. In this study, we analyzed the relationship between audit committee composition and earnings management in the 66 firms listed in the "Índice de Ações com Governança Corporativa Diferenciada" (IGCX) of BM\&FBovespa. The sample was divided into regulated firms $(n=30)$ and unregulated firms $(n=36)$. Firms regulated by government agencies are subject to a specific set of rules and guidelines. The collected data were submitted to the test of difference between means, the correlation test, and chi-square automatic interaction detector analysis. Contrary to our expectations, no difference was found between regulated and unregulated firms with regard to audit committee composition, and no association was detected between audit committee composition and earnings management in the analyzed companies. However, in the segment tree analysis, larger firms displayed a tendency to be regulated and to have lower levels of earnings management and fewer independent directors serving on the audit committee.
\end{abstract}

Keywords: Audit committee. Earnings management. Regulated firms. Regulatory agencies.

\title{
1 Introdução
}

Muito embora as boas práticas de governança corporativa sejam mundialmente consideradas desejáveis, muitas organizações continuam se envolvendo em escândalos financeiros, o que tem motivado o aumento da fiscalização das partes envolvidas e do controle pelos órgãos que fazem parte desse sistema. Dentre as diversas artimanhas organizacionais capazes de comprometer a informação contábil e, consequentemente, o mercado, destaca-se a alteração de resultados por meio de aumento ou diminuição artificial do lucro ou prejuízo, ato conhecido como gerenciamento de resultados.

No contexto estrutural, a governança corporativa constitui um sistema de relações por meio do qual as companhias são dirigidas e monitoradas, sendo possível perceber que há mecanismos de governança internos e externos para o monitoramento da administração (NASCIMENTO; REGINATO, 2010; ROSSETTI; ANDRADE, 2014). Dentre os diversos mecanismos internos aplicáveis, destaca-se o comitê de auditoria, recomendado por diferentes códigos de boas práticas de governança corporativa em todo o mundo, orientando a sua constituição e manutenção com a finalidade de melhorar o processo de governança (BEUREN et al., 2013; FURUTA; SANTOS, 2010).

De natureza supervisora, o comitê de auditoria é constituído de membros nomeados pelo conselho de administração, para prestar-lhe assessoria e apoio especializado (DELOITTE, 2013). Segundo o Instituto Brasileiro de Governança Corporativa (IBGC, 2009, p. 45), "o conselho de administração e o comitê de auditoria devem, permanentemente, monitorar as avaliações e recomendações dos auditores independentes e internos sobre o ambiente de controles e os riscos". Klein (2002) corrobora esse procedimento, ao afirmar que o comitê de auditoria supervisiona o processo de informação financeira da empresa, reunindo-se regularmente com auditores independentes e gerentes financeiros, para rever as demonstrações financeiras, o processo de auditoria e os controles contábeis internos.

Após a promulgação da Lei Sarbanes-Oxley, nos EUA, o comitê de auditoria inevitavelmente ganhou destaque, passando a ser considerado importante instrumento de gestão de risco e elo de comunicação entre conselho de administração, auditores e acionistas, com foco 
e envolvimento no processo e elaboração das demonstrações financeiras. As empresas sentiram-se estimuladas a constituir esse órgão na perspectiva de melhorar os aspectos relacionados à governança (BEUREN et al., 2013; FURUTA; SANTOS, 2010; SILVA et al., 2009), seja de forma voluntária seja para atender à regulamentações específicas.

Ao se referir sobre a regulação de alguns setores da economia, Baioco, Almeida e Rodrigues (2014) explanam que no Brasil a evidenciação contábil para as companhias abertas é extensamente regulada pela Comissão de Valores Mobiliários (CVM), que abrange assuntos contábeis, assim como empresas de capital aberto que atuam em setores específicos da economia e seguem regulação contábil específica. Sorrentino, Teixeira e Vicente (2016), com base em pesquisa empírica, constataram que as empresas sujeitas às normas de um agente regulamentador estão atentas às boas práticas de governança corporativa.

No Brasil, Pinto (2014) ressalta que as agências reguladoras são responsáveis pela gestão de interesses privados, relacionando dez agências brasileiras, a saber: Agência Nacional de Águas (ANA), Agência Nacional de Aviação Civil (Anac), Agência Nacional de Cinema (Ancine), Agência Nacional de Energia Elétrica (Aneel), Agência Nacional de Petróleo (ANP), Agência Nacional de Saúde Complementar (ANS), Agência Nacional de Telecomunicações (Anatel), Agência Nacional de Transporte Aquaviário (Antaq), Agência Nacional de Transporte Terrestre (ANTT), e Agência Nacional de Vigilância Sanitária (Anvisa).

Silva, Galdi e Teixeira (2010) reconhecem que a intervenção do Estado por meio de regulação evidencia regras bem definidas para dirigir ou manter uma relação de equilíbrio dos diversos setores da economia, com efeito através da implantação de uma estrutura de fiscalização e investigação. Sob outra perspectiva, o gerenciamento de resultados funciona como uma intervenção ou distorção proposital no processo de informação financeira externa, com a intenção de obter algum ganho (SCHIPPER, 1989), influenciar o mercado ou evitar a intervenção de regulamentação, dentre diversos aspectos (HEALY; WAHLEN, 1999).

Nesse contexto, o comitê de auditoria, como um órgão de monitoramento interno, defende os interesses dos acionistas de modo a salvaguardar seus investimentos, reduzindo as chances de os gestores agirem em interesse próprio (TEIXEIRA; CAMARGO; VICENTE, 2016), hipoteticamente, por meio de realizações de gerenciamento de resultados. Diante do exposto, este estudo propõe a seguinte questão: Qual a correlação entre as características do comitê de auditoria e a prática de gerenciamento de resultados?

Apesar de diversos estudos - Carcello et al. (2006), Cunha et al. (2014), Klein (2002), Silva et al. (2014), Sun, Lan e Liu (2014), Thiruvadi e Huang (2011), Xie, Davidson III e DaDalt (2003) e Yang e Krishnan (2005) - haverem constatado, em linhas gerais, uma correlação entre as características dos comitês de auditoria e a prática de gerenciamento de resultados, devido, especialmente, à eficácia do órgão no aumento da qualidade da informação financeira, este estudo se diferencia dos demais por investigar essa correlação em empresas que operam em setores regulados e empresas de setores não regulados (BAIOCO; ALMEIDA; RODRIGUES, 2014).

O estudo tem como objetivo geral analisar a correlação entre as características do comitê de auditoria e a prática de gerenciamento de resultados em empresas reguladas e empresas não reguladas participantes do Índice de Ações com Governança Corporativa Diferenciada (IGCX), da Bolsa de Valores, Mercadorias e Futuros (BM\&FBovespa). O estudo tem ainda os seguintes objetivos específicos: (i) descrever as características do comitê de auditoria; (ii) comparar as características do comitê de auditoria nas empresas reguladas com as do comitê nas empresas não reguladas; e (iii) analisar a segmentação, por meio da utilização do Chaid, da classificação das empresas segundo o porte, em relação às características do comitê de auditoria e à prática de gerenciamento de resultados.

Tem sido crescente o interesse pela eficácia do comitê de auditoria, devido ao aumento da preocupação com a qualidade do processo de informação financeira corporativa, em 
decorrência de alguns escândalos contábeis contemporâneos de repercussão mundial (LIN; LI; YANG, 2006). A adoção das boas práticas de governança corporativa é recomendada para corrigir falhas no mercado, devido aos conflitos de agência e à assimetria informacional. E, embora se registre uma evolução nos últimos anos, as pesquisas sobre práticas de gerenciamento de resultados ainda são incipientes no Brasil, comparativamente a outros países (PAULO; LEME, 2009).

Esta pesquisa diferencia-se das demais por investigar o comitê de auditoria e as práticas de gerenciamento de resultados considerando características como gênero (THIRUVADI; HUANG, 2011), tamanho (CUNHA et al., 2014; SILVA et al., 2014; SUN; LAN; LIU, 2014; XIE; DAVIDSON III; DADALT, 2003; YANG; KRISHNAN, 2005), independência (CARCELLO et al., 2006; CUNHA et al., 2014; KLEIN, 2002; XIE; DAVIDSON III; DADALT, 2003; YANG; KRISHNAN, 2005) e expertise (CARCELLO et al., 2006; CUNHA et al., 2014; SILVA et al., 2014; SUN; LAN; LIU, 2014; YANG; KRISHNAN, 2005) do comitê de auditoria em empresas listadas no IGCX. A análise distribui as 66 empresas da amostra em dois grupos, sendo 30 reguladas por agências governamentais e 36 não reguladas (BAIOCO; ALMEIDA; RODRIGUES, 2014; PINTO, 2014). Cabe destacar que o IGCX tem por escopo medir o desempenho de uma carteira teórica constituída por ações de empresas participantes dos segmentos de listagem Novo Mercado, Nível 1 ou Nível 2, da BM\&FBovespa (2015).

\section{Revisão de Literatura}

\subsection{A estrutura do sistema de governança corporativa e o comitê de auditoria}

O IBGC (2009, p. 19) define governança corporativa como o "sistema pelo qual as organizações são dirigidas, monitoradas e incentivadas, envolvendo os relacionamentos entre proprietários, conselho de administração, diretoria e órgãos de controle". Esse sistema reúne os interessados pela empresa que não participam da sua gestão, responsáveis legais e órgãos de monitoramento (NASCIMENTO; REGINATO, 2010). O ambiente e os atores participantes dessa relação resumem-se em propriedade, controle, administração e auditoria e fiscalização, interligados hierarquicamente e originando a estrutura de poder que dá credibilidade à governança corporativa (ROSSETTI; ANDRADE, 2014).

O sistema estrutural proposto por Rossetti e Andrade (2014) baseia-se no triângulo proprietários-conselho-diretoria. Os autores entendem que a estrutura de suporte da alta administração é constituída por: (i) assembleia geral dos acionistas, à qual está vinculado o conselho fiscal; (ii) conselho de administração, com seus comitês técnicos e a auditoria independente; e (iii) diretoria executiva, à qual se reportam as unidades de negócios e de serviços corporativos, entre as quais a auditoria interna.

Segundo San Martin Reyna (2012), o conselho de administração é fundamental para o bom funcionamento da governança corporativa. Códigos de governança recomendam que esse colegiado seja constituído por uma maioria de membros externos (não executivos), devido à sua importante função de monitoramento da empresa (SILVEIRA; BARROS; FAMÁ, 2003). Por conseguinte, o conselho de administração desempenha diversas atividades voltadas para a realização desse monitoramento, que também pode ser delegado a comitês técnicos ou de assessoramento (IBGC, 2009), como, por exemplo, o de auditoria.

A lei norte-americana Sarbanes-Oxley (SOX), vigente desde 2002, surgiu em decorrência de escândalos financeiros envolvendo grandes corporações mundiais, com destaque para o papel da auditoria no cenário das organizações listadas na Bolsa de Valores de Nova Iorque (New York Stock Exchange - Nyse) (DE LUCA et al., 2010; SILVA, 2006). A partir de então, diversos países também atentaram para a importância da auditoria na governança, emergindo o comitê de auditoria como tema de discussão dentro do movimento da governança corporativa e se revelando um dos principais instrumentos para a melhoria e o aperfeiçoamento do processo de prestação de contas (DE LUCA et al., 2010). 
Segundo Firmino, Damascena e Paulo (2010), a auditoria atende a necessidades na economia, no desenvolvimento da empresa e seus negócios, no governo e na prestação de informações para usuários internos e externos. O comitê de auditoria funciona como um instrumento de supervisão fundamental na preservação da integridade do mercado de capitais, sendo constituído por membros independentes do conselho de administração, e com a responsabilidade de supervisionar o processo de preparação e divulgação das informações financeiras, cuidar da integridade dos sistemas de controles internos e preservar o processo de comunicação com auditores independentes (PELEIAS; SEGRETI; COSTA, 2009).

O IBGC (2009) conceitua o comitê de auditoria como um mecanismo interno de governança corporativa, constituído, preferencialmente, por membros do conselho de administração, e que tem a responsabilidade de supervisionar a gestão dos procedimentos internos, bem como assegurar que esses procedimentos sejam íntegros e eficazes, para a produção de relatórios financeiros de qualidade, objetivando a proteção dos acionistas e dos demais usuários da informação contábil.

Com base nas recomendações acadêmicas, a presente pesquisa considera que a atuação do comitê de auditoria permite acreditar que há mais transparência nas atividades sociais da empresa. Entretanto, reguladores, órgãos governamentais e pesquisadores de vários países têm questionado sobre a efetividade desses comitês e seu apoio para a percepção das boas práticas de governança corporativa (FURUTA; SANTOS, 2010). Apesar disso, espera-se dos comitês de auditoria o monitoramento para desestimular a prática de gerenciamento de resultados (KLEIN, 2002).

\subsection{Gerenciamento de resultados e seu relacionamento com o comitê de auditoria}

O gerenciamento de resultados está relacionado à estrutura da governança corporativa, em particular, aos comitês de auditoria e seus mecanismos de controle do processo pertinente aos relatórios financeiros (ALVES; VICENTE, 2013).

Segundo Healy e Wahlen (1999), o gerenciamento de resultados ocorre quando os gestores usam informações financeiras e atividades operacionais alterando relatórios financeiros para iludir stakeholders sobre o desempenho econômico da empresa ou para influenciar o fechamento de contratos que dependem de dados institucionais favoráveis. Niyama, Rodrigues e Rodrigues (2015) entendem que o gerenciamento de resultados ocorre tanto pela manipulação dentro do quadro da licitude consentida pelo sistema contábil, como por meio de verdadeiras fraudes, o que requer uma gestão cuidadosa das lacunas da legislação contábil, admitidas num contexto de flexibilidade e omissão dessas mesmas normas.

De acordo com Rezende e Nakao (2012, p. 9), o gerenciamento de resultados (earnings management) "é um conjunto de práticas adotadas por gestores no intuito de obter resultados contábeis desejáveis, seja pela geração de valor com gerenciamento adequado ou pela criação de artifícios contábeis", e pode ser classificado em accrual earnings management e real earnings management.

Accrual earnings management é a manipulação gerencial dos lucros através de estimativas e métodos contábeis, que não tem impacto direto nos fluxos de caixa. Real earnings management é a manipulação de resultados por meio de atividades operacionais, afetando diretamente o fluxo de caixa ((SUN; LAN; LIU, 2014). Os accruals positivos demonstram o interesse em aumentar evidenciação do lucro, enquanto os accruals negativos refletem o interesse na diminuição dos resultados (SILVA; BEZERRA, 2010).

Martinez (2008) destaca que essa prática compromete a qualidade da informação contábil, criando ineficiências alocativas entre empresas e distribuições de riquezas injustificáveis e causando danos no mercado de capitais. A prática ocorre por uma série de razões, incluindo a pretensão de influenciar a percepção no mercado de ações, para os gestores influenciarem o aumento da sua remuneração, para reduzir a probabilidade de acordos de 
empréstimo e para evitar a intervenção de regulamentação (HEALY; WAHLEN, 1999).

Destarte, o comitê de auditoria atua para mitigar distorções dos resultados das organizações (SILVA et al., 2014), ajudar a reduzir a prática do gerenciamento de resultados, pois compete a seus membros supervisionar o trabalho dos auditores internos, e também a relação entre gestores e auditores, a fim de melhorar a qualidade dos relatórios financeiros da empresa, de modo que a eficácia do comitê não só reduz o gerenciamento de resultados, como faz o auditor ser mais conservador na análise das demonstrações financeiras (THIRUVADI; HUANG, 2011).

Becker et al. (1998) afirmam que a auditoria é uma das formas de reduzir as atitudes oportunistas dos gestores, uma vez que, dentre as suas funções, destaca-se a de verificar a conformidade dos demonstrativos contábeis, reduzindo, assim, a assimetria informacional entre os gestores e os investidores. Para Lin e Hwang (2010), tanto a qualidade da auditoria como a governança possuem a capacidade de reduzir as práticas de gerenciamento de resultados pelas empresas.

Diversos estudos, nacionais e estrangeiros, já investigaram a correlação das características do comitê de auditoria com outras variáveis relacionadas ao gerenciamento de resultados. Em uma amostra de 692 empresas norte-americanas listadas no S\&P 500 nos anos 1992 e 1993, Klein (2002) examinou se as características do comitê de auditoria e as do conselho de administração estão correlacionadas com o gerenciamento de resultados. As conclusões desse estudioso revelam que há correlação negativa entre a independência do comitê de auditoria e do conselho de administração e a prática de gerenciamento de resultados.

Xie, Davidson III e DaDalt (2003) analisaram 282 empresas norte-americanas listadas no índice S\&P 500 nos anos 1992, 1994 e 1996, para verificar o papel do conselho de administração, o do comitê de auditoria e o do comitê executivo na prevenção de práticas de gerenciamento de resultados. Concluíram que a prática de gerenciamento de resultados ocorre com menor frequência quando há independência dos membros dos conselhos e comitês e quando os membros do comitê de auditoria são atuantes nas suas atividades através de reuniões.

Yang e Krishnan (2005) analisaram 250 empresas de capital aberto dos EUA no período de 1996 a 2000, com o objetivo de verificar se havia associação entre as características do comitê de auditoria e medidas de gerenciamento de resultados. A partir de características como independência, número de reuniões, expertise, compra de ações por membros independentes, compra de ações por membros não independentes, participação em outros comitês de auditoria, tempo de experiência no comitê e tamanho, não se encontrou nenhuma associação significativa entre independência e expertise do comitê de auditoria e gerenciamento de resultados. Entretanto, verificou-se uma associação positiva entre a compra de ações por membros independentes e a compra de ações por membros não independentes e gerenciamento de resultados e tempo de experiência no comitê com gerenciamento de resultados.

Carcello et al. (2006) utilizaram uma amostra de 226 empresas não financeiras listadas na Nyse em 2003, para verificar a associação entre expertise do comitê de auditoria, mecanismos de governança corporativa e gerenciamento de resultados. Os autores concluíram que a experiência dos membros do comitê reduz o gerenciamento de resultados e que a governança corporativa melhora a qualidade das informações financeiras institucionais.

Thiruvadi e Huang (2011) examinaram 299 empresas norte-americanas listadas no S\&P Small Cap 600 no exercício de 2003. Investigaram se a diversidade de gênero nos comitês de auditoria tem impacto significativo no gerenciamento de resultados. Concluíram que há evidências consistentes de que a presença de uma diretora no comitê de auditoria restringe o gerenciamento de resultados.

Cunha et al. (2014) investigaram, em 31 empresas listadas na BM\&FBovespa em 2010 e em 33 listadas em 2011, a correlação entre tamanho, independência e expertise do comitê de auditoria e o nível de gerenciamento de resultados. Utilizaram como variáveis independentes o 
valor total do Ativo, a alavancagem, o crescimento das vendas, a internacionalização, a auditoria, a concentração de capital e o setor, para explicar o modelo de regressão linear. $\mathrm{Na}$ amostra de 2010 constataram que apenas três variáveis (alavancagem, auditoria e setor) contribuíam significativamente para o modelo. Na de 2011, não identificaram nenhuma correlação de explicação entre o comportamento do gerenciamento de resultados e as variáveis independentes.

Silva et al. (2014) analisaram 106 empresas listadas no segmento Novo Mercado, da BM\&FBovespa, nos anos 2010, 2011 e 2012. Por meio de métricas como tamanho, formação dos membros e tipo de auditoria, relacionadas ao comitê de auditoria e ao gerenciamento de resultados, verificaram a influência dos aspectos de auditoria na prática de gerenciamento de resultados. Concluíram que a presença de comitê de auditoria, bem como a quantidade de membros e a formação em Contabilidade, não possuem correlação com o gerenciamento de resultados.

Sun, Lan e Liu (2014) examinaram 100 empresas norte-americanas listadas no índice S\&P 1500, no período de 2007 a 2010. Investigaram a eficácia do comitê de auditoria na restrição ao gerenciamento de resultados, analisando a correlação entre as características do órgão (tamanho, independência e expertise) com a manipulação de resultados. Os resultados sugerem que um grande número de membros torna o comitê menos eficaz na restrição ao gerenciamento de resultados.

Com respaldo nos resultados dos estudos empíricos apresentados, delineia-se a seguinte hipótese de pesquisa: Há correlação entre as características do comitê de auditoria e a prática de gerenciamento de resultados.

\section{Procedimentos Metodológicos}

Para se proceder à pesquisa descritiva, a população reúne 181 empresas participantes da carteira teórica do Índice de Ações com Governança Corporativa Diferenciada (IGCX), da BM\&FBovespa, no dia 24 de setembro de 2015. Devido à especificidade do setor financeiro, foram excluídas 38 empresas desse ramo, com o objetivo de evitar distorções no resultado final, seguindo-se o mesmo procedimento adotado por Cunha et al. (2014). Observou-se, ainda, que 14 empresas possuíam ações do tipo ordinárias e preferenciais, concomitantemente, na carteira selecionada, razão pela qual foi considerada um tipo de ação para as empresas em duplicidade.

Em seguida, procedeu-se à análise documental das 129 empresas restantes, realizando checklist de informações no último Formulário de Referência de 2014, no item e subitem 12.7 (Composição dos comitês estatutários e dos comitês de auditoria, financeiro e de remuneração), verificando aquelas que possuíam comitê de auditoria. Identificou-se a ausência desse colegiado em 63 organizações. Dessa forma, a amostra do estudo ficou delimitada em 66 empresas, sendo 30 reguladas e 36 não reguladas, conforme distribuição apresentada na Tabela 1. Ressalta-se que a classificação em empresas reguladas ou não reguladas considerou a associação entre o setor de atuação das organizações, de acordo com a BM\&FBovespa, e os setores regulados pelas agências reguladoras nacionais.

Tabela 1 - Distribuição da amostra do estudo

\begin{tabular}{|c|c|c|}
\hline \multirow{2}{*}{ Agência Reguladora } & \multicolumn{2}{|c|}{ Amostra } \\
\hline & Quantidade de empresas & Proporção (\%) \\
\hline ANEEL (Lei n 9.427/1996) & 11 & 16,7 \\
\hline ANATEL (Lei n 9.472/1997) & 1 & 1,5 \\
\hline ANP (Lei nº 9.478/1997) & 1 & 1,5 \\
\hline ANVISA (Lei nº 9.782/1999) & 6 & 9,1 \\
\hline ANS (Lei n 9.961/2000) & 5 & 7,6 \\
\hline ANA (Lei n 9.984/2000) & 1 & 1,5 \\
\hline ANTT (Lei n $10.233 / 2001)$ & 4 & 6,0 \\
\hline ANTAQ (Lei nº 10.233/2001) & - & 0,0 \\
\hline
\end{tabular}


Sociedade, Contabilidade e Gestão, Rio de Janeiro, v. 12, n. 3, set/dez 2017.

\begin{tabular}{l|c|c}
\hline \multicolumn{1}{c|}{ Agência Reguladora } & \multicolumn{2}{c}{ Amostra } \\
\cline { 2 - 3 } & Quantidade de empresas & Proporção (\%) \\
\hline ANCINE (MP $\left.\mathrm{n}^{\mathbf{0}} 2.228-1 / 2001\right)$ & - & 0,0 \\
\hline ANAC (Lei $\left.\mathrm{n}^{\circ} 11.182 / 2005\right)$ & 1 & 1,5 \\
\hline Não reguladas & 36 & 54,6 \\
\hline TOTAL & $\mathbf{6 6}$ & $\mathbf{1 0 0 , 0}$ \\
\hline
\end{tabular}

Fonte: Elaborada pelos autores.

As variáveis utilizadas nesta pesquisa correspondem às características do comitê de auditoria das empresas da amostra (gênero dos seus membros, tamanho, independência e expertise), gerenciamento de resultados e variáveis de controle como tamanho da empresa e controle acionário. O Quadro 1 apresenta a operacionalização e a fonte de cada variável, assim como alguns estudos empíricos que utilizaram tais variáveis.

Quadro 1 - Gerenciamento de resultados, características do comitê de auditoria e características empresariais utilizadas na pesquisa

\begin{tabular}{|c|c|c|c|c|}
\hline \multicolumn{2}{|r|}{ Variável } & Operacionalização & Fonte de dados & Embasamento teórico \\
\hline \multirow{4}{*}{ 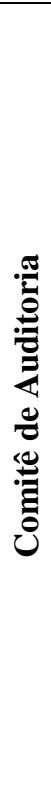 } & Gênero & Presença de mulheres e homens & $\begin{array}{c}\text { Formulário de } \\
\text { Referência - } \\
\text { Item } 12.7\end{array}$ & Thiruvadi e Huang (2011) \\
\hline & Tamanho & Número de membros & $\begin{array}{l}\text { Formulário de } \\
\text { Referência - } \\
\text { Item } 12.7\end{array}$ & $\begin{array}{l}\text { Cunha et al. (2014) } \\
\text { Silva et al. (2014) } \\
\text { Sun, Lan e Liu (2014) } \\
\text { Xie, Davidson III e Dadalt } \\
\text { (2003) } \\
\text { Yang e Krishnan (2005) }\end{array}$ \\
\hline & Independência & $\begin{array}{l}\text { Número de membros } \\
\text { independentes }\end{array}$ & $\begin{array}{l}\text { Formulário de } \\
\text { Referência - } \\
\text { Item } 12.7\end{array}$ & $\begin{array}{l}\text { Carcello et al. (2006) } \\
\text { Cunha et al. (2014) } \\
\text { Klein (2002) } \\
\text { Xie, Davidson III e Dadalt } \\
(2003) \\
\text { Yang e Krishnan (2005) }\end{array}$ \\
\hline & Expertise & $\begin{array}{l}\text { Proporção do número de membros } \\
\text { com formação em Contabilidade, } \\
\text { Finanças ou Auditoria no total de } \\
\text { membros do Comitê }\end{array}$ & $\begin{array}{c}\text { Formulário de } \\
\text { Referência - } \\
\text { Item } 12.7\end{array}$ & $\begin{array}{l}\text { Carcello et al. (2006) } \\
\text { Cunha et al. (2014) } \\
\text { Silva et al. (2014) } \\
\text { Sun, Lan e Liu (2014) } \\
\text { Yang e Krishnan (2005) }\end{array}$ \\
\hline \multicolumn{2}{|c|}{$\begin{array}{l}\text { Gerenciamento de } \\
\text { Resultados }\end{array}$} & $\begin{array}{c}\text { Modelo Kang e Sivaramakrishnan } \\
(\mathrm{KS})\end{array}$ & Economática & $\begin{array}{l}\text { Almeida e Almeida (2009) } \\
\text { Almeida, Lopes e Corrar } \\
\text { (2011) } \\
\text { Cunha et al. (2013) } \\
\text { Seidler (2015) } \\
\text { Silva e Bezerra (2010) } \\
\text { Silva et al. (2014) }\end{array}$ \\
\hline \multicolumn{2}{|r|}{$\begin{array}{l}\text { Tamanho da } \\
\text { Empresa }\end{array}$} & $\begin{array}{l}\text { Logaritmo Natural }(L n) \text { do valor } \\
\text { do Ativo }\end{array}$ & Economática & $\begin{array}{l}\text { Caixe e Krauter (2013) } \\
\text { Choi, Saito e Silva (2015) } \\
\text { Cunha et al. (2014) } \\
\text { Freguete, Nossa e Funchal } \\
(2015) \\
\text { Gonçalves et al. (2013) }\end{array}$ \\
\hline \multicolumn{2}{|c|}{ Controle Acionário } & $\begin{array}{c}\text { Institucional, Estatal, Estrangeiro } \\
\text { ou Familiar }\end{array}$ & $\begin{array}{l}\text { Formulário de } \\
\text { Referência - } \\
\text { Item } 15.1\end{array}$ & $\begin{array}{l}\text { Caixe e Krauter (2013) } \\
\text { Marques, Guimarães } \\
\text { Peixoto (2015) } \\
\text { Parente, Vasconcelos e De } \\
\text { Luca (2014) } \\
\text { Peixoto e Buccini (2013) } \\
\text { Silveira e Barros (2008) }\end{array}$ \\
\hline
\end{tabular}

Fonte: Elaborado pelos autores. 
O gerenciamento de resultados utiliza o modelo Kang e Sivaramakrishnan (KS). Martinez (2008) ensina que o modelo KS (Kang \& Silvaramakrishnan) para o cálculo do gerenciamento de resultados nas empresas atuantes no país é mais propício, devido ao aspecto inflacionário. Ademais, segundo Mota et al. (2015), o modelo KS é um dos mais utilizados como proxi para gerenciamento de resultados. O modelo utiliza contas do Balanço Patrimonial, de modo a explicar a dimensão dos Accruals Totais (AT) e dos Accruals Discricionários (AD), conforme equações 1 e 2 , respectivamente.

$$
\begin{array}{ll}
\mathrm{AT}_{\mathrm{it}}=\varphi_{0}+\varphi_{1}\left[\delta_{1} \operatorname{Rec}_{\mathrm{it}}\right]+\varphi_{2}\left[\delta_{2} \mathrm{Desp}_{\mathrm{it}}\right]+\varphi_{3}\left[\delta_{3} \mathrm{At}_{\text {Imob }}\right]+\varepsilon_{\mathrm{it}} & \text { (Equação 1) } \\
\mathrm{AD}_{\mathrm{it}}=\mathrm{AT}_{\mathrm{it}}-\left\{\varphi_{0}+\varphi_{1}\left[\delta_{1} \operatorname{Rec}_{\mathrm{it}}\right]+\varphi_{2}\left[\delta_{2} \mathrm{Des}_{\mathrm{it}}\right]+\varphi_{3}\left[\delta_{3} \mathrm{At}_{\mathrm{Imob}} \mathrm{Imob}_{\mathrm{it}}\right]\right\} & \text { (Equação 2) }
\end{array}
$$

Em que:

$\mathrm{AT}_{\mathrm{it}}=$ Acumulações Totais $=(\text { CGL menos Depreciação \& Amortização })_{\mathrm{t}}$

$\operatorname{Rec}_{\text {it }}=$ Receita Líquida (excluindo tributação)

Desp $_{\text {it }}=$ Custos e Despesas Operacionais antes da Depreciação \& Amortização

CGL = Capital de Giro Líquido, excluindo as disponibilidades, financiamentos de curto prazo e provisão de Impostos a Pagar

At.Imob ${ }_{\text {it: }}$ Ativo Imobilizado e Ativo Diferido

C.Receb $b_{\mathrm{i}, \mathrm{t}-1}=$ Contas a Receber no período $t-1$

DEPREC $_{\mathrm{i}, \mathrm{t}-1}=$ Despesas de Depreciação

$\delta_{1}=\mathrm{C} \cdot \operatorname{Receb}_{\mathrm{i}, \mathrm{t}-1} / \mathrm{Rec}_{\mathrm{i}, \mathrm{t}-1}$, onde AR (Contas a Receber)

$\delta_{2}=\left(\Delta \mathrm{CG}-\mathrm{CRec}_{\mathrm{it}}\right) / \operatorname{Desp}_{\mathrm{i}, \mathrm{t}-1}$

$\delta_{3}=$ DEPREC $_{\mathrm{i}, \mathrm{t}-1} / \mathrm{A} \cdot \mathrm{Imob}_{\mathrm{i}, \mathrm{t}-1}$

$\mathrm{Rec}_{\mathrm{it}}, \mathrm{Desp}_{\mathrm{it}}$, At.Imob $\mathrm{it}_{\mathrm{i}}$, essas variáveis são escaladas em termos de ativos totais.

Considerando as equações 1 e 2, o gerenciamento de resultados é evidenciado pelos Accruals Discricionários (AD) das empresas amostra, que foram identificados pelos erros da regressão linear múltipla $\left(\varepsilon_{\mathrm{it}}\right)$ extraídos de cada firma.

Na realização dos procedimentos voltados para o alcance dos objetivos propostos, este estudo utiliza o teste de diferença entre médias, o teste de correlação e o teste de detecção de interação automática do qui-quadrado (Chaid), que apresenta a árvore de segmentação (dendograma). O tratamento dos dados deu-se com o auxílio do aplicativo Statistical Package for the Social Sciences (SPSS), versão 22.

\section{Resultados}

\subsection{Características dos comitês de auditoria das empresas analisadas}

A identificação das características dos comitês de auditoria das 66 empresas da amostra levou em conta alguns aspectos quantitativos relacionados aos seus membros, como o número total, o número de independentes e a quantidade com formação em Contabilidade, Finanças e Auditoria. Feito isso, foi possível verificar que apenas 19,7\% das empresas possuem comitê constituído por homens e mulheres, enquanto os demais $80,3 \%$ são constituídos somente por homens. Esse resultado coincide com aquele encontrado por Thiruvadi e Huang (2011) no tocante às 299 empresas norte-americanas listadas no S\&P Small Cap 600 no exercício de 2003.

Thiruvadi e Huang (2011) constataram, ainda, a participação de no máximo duas mulheres em comitês de auditoria de 2,3\% das empresas, resultado semelhante ao encontrado nesta pesquisa, ou seja, máximo de duas mulheres em 3\% das empresas. Ressalta-se que a presença de duas mulheres foi observada no comitê de auditoria da CCR S. A., do setor de transporte, regulado pela ANTT, e no da Paranapanema S. A., do setor de metalurgia e siderurgia, que não é regulado.

Pesquisas realizadas por Alves et al. (2010), Bruère, Mendes-da-Silva e Santos (2007), Machado e Beuren (2015) e Van der Walt et al. (2006) identificaram maior presença masculina 
na estrutura da governança, indicando uma tendência de concentração de homens na composição dos órgãos. Os estudos ressaltam ainda que as mulheres possuem características conservadoras, comportamento menos agressivo e menor suscetibilidade à adesão a práticas antiéticas. Enfim, a diversidade de gênero na composição dos órgãos de governança resulta num potencial que contribui para aumentar a qualidade da estratégia das organizações (ALVES et al., 2010).

A Tabela 2 apresenta a distribuição dos membros de comitê de auditoria nas empresas pesquisadas. Observa-se que a maioria das empresas $(69,7 \%)$ possui entre 1 e 3 membros no comitê, o que dá uma média é de 3,4 por comitê, com mínimo de 1 e máximo de 8 . Esses resultados corroboram os achados de Cunha et al. (2014), segundo os quais as empresas com comitê de auditoria que possuíam entre 1 e 3 membros correspondiam a 80,6\% no ano 2010 e a 72,7\% no ano 2011. Entretanto, os achados da pesquisa de Xie, Davidson III e Dadalt (2003) diferem no tocante à média e aos números mínimo e máximo de membros, com 4, 5, 2 e 12, respectivamente.

Tabela 2 - Tamanho e independência do comitê de auditoria em empresas reguladas e em empresas não reguladas

\begin{tabular}{|c|c|c|c|c|c|c|c|c|c|c|c|c|}
\hline \multirow{3}{*}{ Faixa } & \multicolumn{6}{|c|}{ Tamanho } & \multicolumn{6}{|c|}{ Independência } \\
\hline & \multicolumn{2}{|c|}{ Total } & \multicolumn{2}{|c|}{ Regulada } & \multicolumn{2}{|c|}{$\begin{array}{c}\text { Não } \\
\text { Regulada }\end{array}$} & \multicolumn{2}{|c|}{ Total } & \multicolumn{2}{|c|}{ Regulada } & \multicolumn{2}{|c|}{ Não Regulada } \\
\hline & Qtd. & $\begin{array}{c}\text { Prop. } \\
(\%)\end{array}$ & Qtd. & $\begin{array}{c}\text { Prop. } \\
(\%) \\
\end{array}$ & Qtd. & $\begin{array}{c}\text { Prop. } \\
(\%)\end{array}$ & Qtd. & $\begin{array}{c}\text { Prop. } \\
(\%) \\
\end{array}$ & Qtd. & $\begin{array}{c}\text { Prop. } \\
(\%)\end{array}$ & Qtd. & $\begin{array}{c}\text { Prop. } \\
(\%)\end{array}$ \\
\hline 0 & - & - & - & - & - & - & 17 & 25,8 & 7 & 10,6 & 10 & 15,2 \\
\hline $1-3$ & 46 & 69,7 & 22 & 33,3 & 24 & 36,4 & 48 & 72,7 & 22 & 33,3 & 26 & 39,4 \\
\hline $4-6$ & 18 & 27,3 & 8 & 12,1 & 10 & 15,2 & 1 & 1,5 & 1 & 1,5 & - & - \\
\hline $7-9$ & 2 & 3,0 & - & - & 2 & 3,0 & - & - & - & - & - & - \\
\hline Total & 66 & 100,0 & 30 & 45,4 & 36 & 54,6 & 66 & 100,0 & 30 & 45,4 & 36 & 54,6 \\
\hline
\end{tabular}

Fonte: Elaborada pelos autores.

Em relação ao tamanho do comitê, salienta-se que a Arezzo Indústria e Comércio S. A., do setor têxtil e vestuário, e a Eternit S. A., do setor de construção civil, material de construção e decoração, ambas não reguladas, possuem, respectivamente, sete e oito membros no comitê de auditoria. Paradoxalmente, a Companhia de Locação das Américas, pertencente ao setor de prestação de serviços de transporte e logística, e também não regulada, possui apenas um membro no comitê. Em seu Formulário de Referência, a empresa informa que não atende aos requisitos instituídos pela Instrução $\mathrm{CVM} \mathrm{n}^{\circ} 308$, a qual dispõe sobre o registro e o exercício da atividade de auditoria independente, isso certamente devido ao fato de seu único membro possuir formação em Engenharia.

Quanto à independência dos membros, $72,7 \%$ da amostra possuem até três membros com essa característica, confirmando os resultados de Cunha et al. (2014), que também encontraram entre um e três membros independentes nos exercícios de 2010 (100\%) e 2011 (97\%). Destaca-se que em nove empresas reguladas, sendo três pela Anvisa, duas pela ANTT, duas pela Aneel, uma pela Anac e uma pela ANS, e em oito não reguladas, o comitê de auditoria é integralmente constituído por membros independentes, destacando-se a M. Dias Branco S. A. Indústria e Comércio de Alimentos, cujo comitê reúne o maior número de membros independentes: quatro.

A expertise dos membros foi acentuada em cinco empresas da amostra $(7,6 \%)$, em cujos comitês todos os membros possuem formação em Contabilidade, Finanças e Auditoria, sendo duas reguladas (Companhia de Saneamento Básico do Estado de São Paulo, regulada pela ANA, e Companhia Energética de Minas Gerais, regulada pela Aneel) e três não reguladas (Fibria Celulose S. A., Positivo Informática S. A. e Rodobens Negócios Imobiliários S. A.). Enquanto isso, 13 empresas $(19,7 \%)$ não possuem participante no comitê com formação 
naquelas áreas. Entretanto, algumas peculiaridades chamam a atenção no tocante à formação do comitê de auditoria em empresas reguladas pela ANS, como a Odontoprev S. A., em que um dos membros é odontólogo, e a Fleury S. A., cujo comitê tem um médico. A presença desses profissionais nos comitês de auditoria das duas empresas justifica-se pelo fato de ambas pertencerem ao setor de saúde e necessitar de controles específicos.

Após a apresentação das características dos comitês de auditoria das empresas da amostra, passou-se à análise quantitativa, por meio da aplicação de testes para comparar as empresas reguladas com as empresas não reguladas através das características dos comitês de auditoria, com vistas à verificação da validade da hipótese do estudo.

\subsection{Comparação entre as características do comitê de auditoria em empresas reguladas e em empresas não reguladas}

Para comparar as empresas reguladas com as empresas não reguladas quanto às características do comitê de auditoria, realizou-se o teste Kolmogorov-Smirnov de normalidade dos dados. Os resultados da aplicação do teste sugerem a rejeição da hipótese nula para todas as variáveis, de modo a se constatar a não normalidade dos dados, devido ao fato de o p-valor explicitar valor inferior ao nível de significância de 5\%. Por conseguinte, para a verificação da existência de diferença entre empresas reguladas e empresas não reguladas quanto às características do comitê de auditoria e gerenciamento de resultados, recomenda-se o teste não paramétrico de Mann-Whitney, conforme Tabela 3.

Tabela 3 - Teste de diferença de médias

\begin{tabular}{l|c|c}
\hline \multicolumn{1}{c|}{ Variável } & p-valor & Decisão sobre a hipótese \\
\hline Gênero & 0,620 & Não rejeitar \\
\hline Tamanho do comitê & 0,267 & Não rejeitar \\
\hline Independência & 0,402 & Não rejeitar \\
\hline Expertise & 0,602 & Não rejeitar \\
\hline Accruals discricionários & 0,230 & Não rejeitar \\
\hline
\end{tabular}

Fonte: Elaborada pelos autores.

$\mathrm{Na}$ Tabela 3, identifica-se a não rejeição da hipótese nula para todas as variáveis, considerando-se que o p-valor é maior do que o nível de significância de 5\%, o que indica uma não similaridade estatística entre as médias das características do comitê de auditoria e do gerenciamento de resultados nos dois grupos de empresas.

Diferentemente do que era esperado de início, não se constatou que o gênero dos membros, o tamanho do comitê, a independência dos membros, a expertise dos membros e os accruals discricionários são estatisticamente diferentes quando as empresas reguladas são comparadas com as não reguladas. Esse resultado corrobora os achados de Baioco, Almeida e Rodrigues (2014), segundo os quais não há diferenças significativas entre empresas reguladas e empresas não reguladas para medidas de índice de suavização (gerenciamento de resultados) e medidas baseadas em variações no desempenho econômico por meio de decisões operacionais. Após a comparação, procedeu-se à verificação da correlação proposta pela pesquisa.

\subsection{Correlação entre accruals discricionários, características do comitê de auditoria e características empresariais}

Para atender ao objetivo de verificar a correlação entre as características do comitê de auditoria e a prática de gerenciamento de resultados em empresas reguladas e em empresas não reguladas, as Tabelas 4 e 5 mostram a correlação de Spearman entre accruals discricionários, características do comitê de auditoria e características empresariais. A Tabela 4 trata dos accruals discricionários para diminuição do lucro. 
Tabela 4 - Correlação entre accruals discricionários para diminuição do lucro, características do comitê de auditoria e características empresariais

\begin{tabular}{l|ccccccc}
\hline \multicolumn{1}{c|}{ Variável } & Accruals & Gênero & $\begin{array}{c}\text { Tamanho } \\
\text { do comitê }\end{array}$ & Independência & Expertise & $\begin{array}{c}\text { Tamanho } \\
\text { da empresa }\end{array}$ & $\begin{array}{c}\text { Controle } \\
\text { acionário }\end{array}$ \\
\hline Accruals & 1,000 & & & & & & \\
$\begin{array}{l}\text { Gênero } \\
\begin{array}{l}\text { Tamanho do } \\
\text { comitê }\end{array}\end{array}$ & 0,297 & 1,000 & & & & & \\
$\begin{array}{l}\text { Independência } \\
\text { Expertise }\end{array}$ & $-0,098$ & $0,368\left(^{*}\right)$ & 1,000 & & & & \\
$\begin{array}{l}\text { Tamanho da } \\
\text { empresa }\end{array}$ & $-0,072$ & $-0,243$ & 0,242 & 1,000 & & & \\
$\begin{array}{l}\text { Controle } \\
\text { acionário }\end{array}$ & $-0,098$ & 0,114 & 0,013 & $-0,337\left(^{*}\right)$ & $-0,096$ & 1,000 & \\
\hline
\end{tabular}

(*) Nível de significância de $10 \%$.

Fonte: Elaborada pelos autores.

Na Tabela 4, observa-se que nas empresas pesquisadas não há correlação entre a prática de gerenciamento de resultados para diminuição do lucro e as características do comitê de auditoria. Esse resultado corrobora os achados de Silva et al. (2014), segundo os quais não há correlação entre accruals discricionários para diminuição do lucro, quantidade de membros no comitê e membros do comitê com formação em Contabilidade.

Entretanto, considerando-se o nível de significância de $10 \%$, constatou-se uma correlação positiva entre os gêneros dos membros e o tamanho do comitê, e uma correlação negativa entre a independência dos membros do comitê e o tamanho da empresa.

A Tabela 5 expõe os accruals discricionários para aumento do lucro. Os resultados exibem uma correlação negativa entre accruals discricionários para aumento do lucro e o tamanho da empresa ao nível de significância de $10 \%$, resultado que corrobora os achados de Carcello et al. (2006).

Tabela 5 - Correlação entre accruals discricionários para aumento do lucro, características do comitê de auditoria e características empresariais

\begin{tabular}{|c|c|c|c|c|c|c|c|}
\hline Variável & Accruals & Gênero & $\begin{array}{l}\text { Tamanho } \\
\text { do comitê }\end{array}$ & Independência & Expertise & $\begin{array}{c}\text { Tamanho } \\
\text { da empresa }\end{array}$ & $\begin{array}{l}\text { Controle } \\
\text { acionário }\end{array}$ \\
\hline Accruals & 1,000 & & & & & & \\
\hline Gênero & $-0,232$ & 1,000 & & & & & \\
\hline $\begin{array}{l}\text { Tamanho do } \\
\text { comitê }\end{array}$ & 0,127 & 0,157 & 1,000 & & & & \\
\hline Independência & $-0,055$ & 0,260 & $-0,050$ & 1,000 & & & \\
\hline Expertise & $-0,242$ & 0,172 & 0,079 & $0,378(* *)$ & 1,000 & & \\
\hline $\begin{array}{l}\text { Tamanho da } \\
\text { empresa }\end{array}$ & $\begin{array}{c}- \\
0,319(*)\end{array}$ & $-0,034$ & $-0,067$ & 0,219 & $-0,013$ & 1,000 & \\
\hline $\begin{array}{l}\text { Controle } \\
\text { acionário }\end{array}$ & $-0,086$ & 0,042 & $-0,100$ & $-0,137$ & $-0,204$ & $-0,231$ & 1,000 \\
\hline
\end{tabular}

(*) Nível de significância de 10\%; (**) Nível de significância de 5\%.

Fonte: Elaborada pelos autores. 
Na Tabela 5, observa-se uma correlação entre a independência dos membros do comitê e a sua expertise ao nível de significância de 5\%. Ressalta-se que Xie, Davidson III e DaDalt (2003) não identificaram nenhuma correlação entre gerenciamento de resultados e tamanho do comitê de auditoria, em empresas norte-americanas listadas no índice S\&P 500; que Yang e Krishnan (2005) não encontraram correlação entre gerenciamento de resultados, independência e expertise em companhias abertas norte-americanas; e que Cunha et al. (2014) não identificaram correlação entre gerenciamento de resultados e tamanho, independência e expertise no período de 2011, em empresas listadas na BM\&FBovespa.

Dessa forma, salienta-se que, por não haver correlação entre accruals discricionários para aumento e diminuição do lucro e as características do comitê de auditoria nas empresas pesquisadas, rejeita-se a hipótese de que há correlação entre as características do comitê de auditoria e a prática de gerenciamento de resultados.

Contudo, adicionalmente aplicou-se o método de detecção de interação automática do qui-quadrado (Chaid), para estimar as variáveis preditoras da classificação das empresas segundo o tamanho (pequeno, médio e grande porte). Essa técnica de dependência entre variáveis caracteriza-se por possuir uma variável dependente que se deseja explicar através de um conjunto de variáveis independentes, também conhecidas como preditoras (MERCADO, 1998).

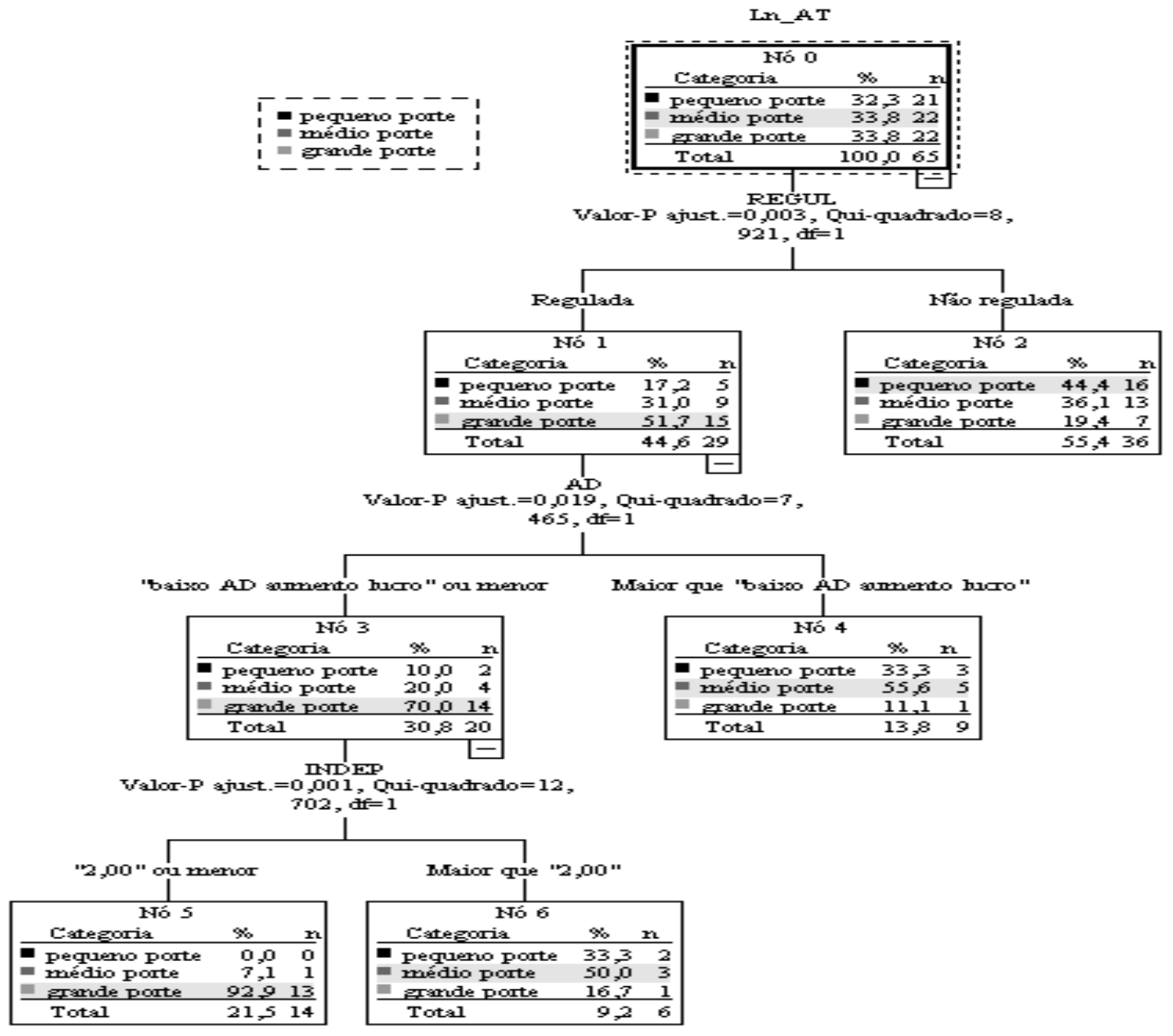

Figura 1 - Árvore de segmentação do tamanho da empresa Fonte: Elaborada pelos autores. 
Nesse teste estatístico foram utilizados como variáveis preditoras os accruals discricionários, gêneros dos membros do comitê, tamanho do comitê, independência dos membros e expertise dos membros, além do controle acionário. A Figura 1 apresenta a árvore com os resultados da associação em questão nas empresas da amostra.

Na Figura 1, verifica-se que variáveis preditoras como regulação das empresas, nível dos accruals discrionários e independência dos membros do comitê de auditoria são capazes de explicar o tamanho das empresas.

Considerando-se a segmentação apresentada na Figura 1, pode-se constatar que a regulação (empresa regulada ou não regulada) é a variável que melhor explica o tamanho da empresa, sendo que mais da metade das empresas de grande porte $(51,7 \%)$ é regulada, enquanto nas empresas de pequeno porte $(44,4 \%)$ ressalta-se a não regulação.

Na sequência, verifica-se uma segunda subdivisão, que gera dois nós filhos, explicados pela variável nível dos accruals discrionários, do que se infere que a maioria das empresas reguladas de grande porte $(70 \%)$ possui um baixo nível de gerenciamento de resultados. Na mesma linha de raciocínio, Baioco, Almeida e Rodrigues (2014) constataram que as empresas de setores regulados possuem nível de gerenciamento de resultados mais baixo.

Em seguida, observa-se que o nó pai número 3 é subdividido pela variável quantidade de membros com independência dos comitês de auditoria, sendo que quase a totalidade das empresas de grande porte $(92,9 \%)$, com baixo nível de gerenciamento de resultados e da categoria regulada, possui menos de três membros independentes. Ressalta-se que a pesquisa de Klein (2002) indicou resultado semelhante em relação à independência dos membros do comitê de auditoria e a um baixo nível de gerenciamento de resultados na sua amostra constituída de empresas norte-americanas listadas no S\&P 500.

\section{Considerações Finais}

Analisou-se a correlação entre as características do comitê de auditoria e as práticas de gerenciamento de resultados em empresas reguladas e empresas não reguladas listadas no IGCX, da BM\&FBovespa. Adicionalmente, procurou-se identificar as características dos comitês de auditoria e as características empresariais da amostra. Para tanto, foram levantadas informações qualitativas e quantitativas, referentes ao ano 2014, por meio da análise do Formulário de Referência das 66 empresas do IGCX com comitê de auditoria constituído, e dados disponíveis para operacionalização da pesquisa.

Os resultados mostram comitês de auditoria em sua maioria constituídos somente por homens, e inexistência de comitês formados somente por mulheres. Esses comitês possuem no mínimo um e no máximo oito membros, sendo que a sua grande maioria possui entre um e três membros. A maioria dos comitês possui entre um e três membros independentes, e em cinco empresas todos os membros do comitê detinham formação em Contabilidade, Finanças e Auditoria. Os resultados da comparação de características como gênero, tamanho, independência, expertise dos membros dos comitês de auditoria e accruals discricionários entre empresas reguladas e empresas não reguladas não indicaram diferenças entre elas, diferentemente do esperado no início. Os resultados da análise de correlação viabilizam depreender que, nas empresas da amostra, não há correlação entre as características dos comitês de auditoria e a prática de gerenciamento de resultados. Entretanto, observou-se uma correlação negativa entre gerenciamento de resultados e tamanho da empresa, o que possibilitou a verificação das variáveis preditoras regulação, accruals discricionários e independência dos membros do comitê para explicar a classificação em pequeno, médio e grande porte.

Os resultados do relacionamento aqui investigado reforçam os achados de Cunha et al. (2014) e Silva et al. (2014), que também não encontraram correlação significativa entre variáveis que caracterizam os comitês de auditoria e a prática de gerenciamento de resultados. Entretanto, na presente pesquisa foi possível verificar, por meio da análise da árvore de 
segmentação, que as empresas de grande porte apresentam baixo nível de gerenciamento de resultados, são reguladas e possuem baixo número de membros independentes no comitê de auditoria.

A literatura predominante sobre estrutura do sistema de governança corporativa afirma que os órgãos que se relacionam são representados por atores interessados pela organização constituintes da tríade proprietários-conselho-diretoria. Tratando-se da atividade de monitoramento da empresa desempenhada pelo conselho de administração, esse colegiado pode confiar em órgãos de assessoramento ou comitês técnicos, sendo que esta pesquisa destacou o comitê de auditoria como uma alternativa para a redução de práticas de gerenciamento de resultados.

Entretanto, diferentemente de estudos estrangeiros, predominantemente, em empresas norte-americanas, os achados desta pesquisa mostraram a inexistência de correlação entre accruals discricionários e gênero, tamanho, independência e expertise dos membros dos comitês de auditoria, sinalizando a necessidade de estudos mais aprofundados acerca da temática no mercado de capitais brasileiro.

Diante das limitações da pesquisa quanto ao tamanho da amostra, recomenda-se a realização de novos estudos com maior número de empresas, agregando outras variáveis que caracterizem comitê de auditoria, aplicando testes estatísticos mais robustos e utilizando estudos comportamentais (séries longitudinais), por se tratar de característica marcante nos estudos estrangeiros e, até mesmo, estudos comparativos entre empresas de economias emergentes e de mercados desenvolvidos.

\section{Referências}

ALMEIDA, J. E. F.; ALMEIDA, J. C. G. Auditoria e earnings management: estudo empírico nas empresas abertas auditadas pelas Big Four e demais firmas de auditoria. Revista Contabilidade \& Finanças, v. 20, n. 50, p. 62-74, 2009.

ALMEIDA, J. E. F.; LOPES, A. B.; CORRAR, L. J. Gerenciamento de resultados para sustentar a expectativa do mercado de capitais: impactos no índice market-to-book. Advances in Scientific and Applied Accounting, v. 4, n. 1, p. 44-62, 2011.

ALVES, C. A. M.; ZANON, R. S.; SAVOIA, J. R. F.; ROCHA, K. C.; MACHADO FILHO, C. A. P. Governança corporativa e conselhos de administração de bolsas com atuação internacional: similaridades e distinções. Gestão \& Regionalidade, v. 26, n. 76, 2010.

ALVES, C. F.; VICENTE, E. F. R. Does the latin model of corporate governance perform worse than other models in preventing earnings management?. Applied Financial

Economics, v. 23, n. 21, p. 1663-1673, 2013.

BAIOCO, V.; ALMEIDA, J. E.; RODRIGUES, A. Incentivos da regulação de mercados sobre o nível de suavização de resultados. Contabilidade Vista \& Revista, v. 24, n. 2, p. 110-136, 2014.

BECKER, C. L.; DEFOND, M. L.; JIAMBALVO, J.; SUBRAMANYAM, K. R. The effect of audit quality on earnings management. Contemporary Accounting Research, v. 15, n. 1, p. 1-24, 1998.

BEUREN, I. M.; NASS, S.; THEISS, V.; CUNHA, P. R. Caracterização proposta para o comitê de auditoria no código de governança corporativa do Brasil e de outros países. Revista de Educação e Pesquisa em Contabilidade, v. 7, n. 4, p. 407-423, 2013. 
BM\&FBOVESPA - Bolsa de Valores, Mercadorias e Futuros. Índice de ações com governança corporativa diferenciada - IGCX. 2015. Disponível em:

<http://www.bmfbovespa.com.br/indices/ResumoIndice.aspx? Indice=IGC\&Idioma=pt-br > Acesso em: 28 out. 2015.

BRUÈRE, A. J.; MENDES-DA-SILVA, W.; SANTOS, J. F. Aspectos da governança corporativa de empresas listadas na Bovespa: um estudo exploratório sobre a composição e perfil dos conselhos de administração. Revista de Administração e Contabilidade da Unisinos, v. 4, n. 2, p. 149-159, 2007.

CAIXE, D. F.; KRAUTER, E. A influência da estrutura de propriedade e controle sobre o valor de mercado corporativo no Brasil. Revista Contabilidade \& Finanças, v. 24, n. 62, p. 142-153, 2013.

CARCELlO, J. V.; HOLLINGSWORTH, C. W.; KLEIN, A.; NEAL, T. L. Audit committee financial expertise, competing corporate governance mechanisms, and earnings management. Competing Corporate Governance Mechanisms, and Earnings Management, v. 20, n. 4, p. 351-37, 2006.

CHOI, D. Y.; SAITO, R.; SILVA, V. A. B. Capital structure and staff salary: empirical evidence in Brazil. Revista de Administração Contemporânea, v. 19, n. 2, p. 249-269, 2015 .

CUNHA, P. R.; SANT’ANA, S. V.; THEIS, M. B.; KRESPI, N. T. Características do comitê de auditoria e os reflexos no gerenciamento de resultados nas empresas listadas na BM\&FBovespa. Revista de Contabilidade do Mestrado em Ciências Contábeis da UERJ, v. 18, n. 3, p. 2-19, 2013.

CUNHA, P. R.; HILLESHEIM, T.; FAVERI, D. B.; RODRIGUES JÚNIOR, M. M. Características do comitê de auditoria e o gerenciamento de resultados: um estudo nas empresas listadas na BM\&FBovespa. Revista de Contabilidade e Organizações, v. 8, n. 22, p. 15-25, 2014.

DE LUCA, M. M. M.; MARTINS, L. C.; MAIA, A. B. G. R.; COELHO, A. C. D. Os mecanismos de auditoria evidenciados pelas empresas listadas nos níveis diferenciados de governança corporativa e no Novo Mercado da Bovespa. Contabilidade Vista \& Revista, v. 21, n. 1, p. 101-130, 2010.

DELOITTE. Centro de Governança Corporativa. Guia prático para os comitês de auditoria das empresas brasileiras: da visão à operação. Reino Unido: Deloitte, 2013.

FIRMINO, J. E.; DAMASCENA, L. G.; PAULO, E. Qualidade da auditoria no Brasil: um estudo sobre a atuação das auditorias independentes denominadas Big Four. Sociedade, Contabilidade e Gestão, v. 5, n. 3, p. 40-50, 2010.

FREGUETE, L. M.; NOSSA, V.; FUNCHAL, B. Responsabilidade social corporativa e desempenho financeiro das empresas brasileiras na crise de 2008. Revista de Administração Contemporânea, v. 19, n. 2, p. 232-248, 2015. 
FURUTA, F.; SANTOS, A. Comitê de auditoria versus conselho fiscal adaptado: a visão dos analistas de mercado e dos executivos das empresas que possuem ADRs. Revista Contabilidade \& Finanças, v. 21, n. 53, p. 1-23, 2010.

GONÇALVES, R. S.; MEDEIROS, O. R.; NIYAMA, J. K.; WEFFORT, E. F. J. Social disclosure e custo de capital próprio em companhias abertas no Brasil. Revista Contabilidade \& Finanças, v. 24, n. 62, p. 113-124, 2013.

HEALY, P. M.; WAHLEN, J. M. A review of the earnings management literature and its implications for standard setting. Accounting Horizons, v. 13, n. 4, p. 365-383, 1999.

IBGC - Instituto Brasileiro de Governança Corporativa. Código das melhores práticas de governança corporativa. 4. ed. São Paulo: IBGC, 2009.

KLEIN, A. Audit committee, board of director characteristics, and earnings management. Journal of Accounting and Economics, v. 33, n. 3, p. 375-400, 2002.

LIN, J. W.; HWANG, M. I. Audit quality, corporate governance, and earnings management: A meta-analysis. International Journal of Auditing, v. 14, n. 1, p. 57-77, 2010.

LIN, J. W.; LI, J. F.; YANG, J. S. The effect of audit committee performance on earnings quality. Managerial Auditing Journal, v. 21, n. 9, p. 921-933, 2006.

MACHADO, D. G.; BEUREN, I. M. Política de remuneração de executivos: um estudo em empresas industriais brasileiras, estadunidenses e inglesas. Gestão \& Regionalidade, v. 31, n. 92, p. 4-24, 2015.

MARQUES, T. A.; GUIMARÃES, T. M.; PEIXOTO, F. M. A concentração acionária no Brasil: análise dos impactos no desempenho, valor e risco das empresas. Revista de Administração Mackenzie, v. 16, n. 4, p. 100-133, 2015.

MARTINEZ, A. L. Detectando earnings management no Brasil: estimando os accruals discricionários. Revista Contabilidade \& Finanças, v. 19, n. 46, p. 7-17, 2008.

MERCADO, R. M. E. Las aplicaciones del análisis de segmentación: el procedimiento Chaid. Empiria - Revista de Metodología de Ciencias Sociales, n. 1, p. 13-49, 1998.

MOTA, R. H. G.; SILVA FILHO, A. C. C.; OLIVEIRA, A. F.; PAULO, E. Previsão de lucro por analistas e gerenciamento de resultados: evidências empíricas no mercado acionário brasileiro. In: CONGRESSO USP DE CONTROLADORIA E CONTABILIDADE, 15., 2015. Anais... São Paulo: USP, 2015.

NASCIMENTO, A. M.; REGINATO, L. Controladoria: instrumento de apoio ao processo decisório. São Paulo: Atlas, 2010.

NIYAMA, J. K.; RODRIGUES, A. M. G.; RODRIGUES, J. M. Algumas reflexões sobre contabilidade criativa e as normas internacionais de contabilidade. Revista Universo Contábil, v. 11, n. 1, p. 69-87, 2015. 
PARENTE, P. H. N.; VASCONCELOS, A. C.; DE LUCA, M. M. M. Influência da estrutura de propriedade horizontal e da estrutura de propriedade piramidal na governança das maiores empresas de capital aberto do Brasil. In: CONGRESSO USP DE CONTROLADORIA E CONTABILIDADE, 14., 2014. Anais... São Paulo: USP, 2014.

PAULO, E.; LEME, J. R. Gerenciamento de resultados contábeis e o anúncio dos resultados contábeis pelas companhias abertas brasileiras. Revista Universo Contábil, v. 5, n. 4, p. 27 43, 2009.

PEIXOTO, F. M.; BUCCINI, A. R. A. Separação entre propriedade e controle e sua relação com desempenho e valor de empresas brasileiras: onde estamos?. Revista de Contabilidade e Organizações, v. 7, n. 18, 2013.

PELEIAS, I. R; SEGRETI, J. B.; COSTA, C. A. Comitê de auditoria ou órgãos equivalentes no contexto da Lei Sarbanes-Oxley: estudo da percepção dos gestores de empresas brasileiras emitentes de American Depositary Receipts - ADRs. Contabilidade Vista \& Revista, v. 20, n. 1, p. 41-65, 2009.

PINTO, P. D. Tribunal de Contas da União, agências reguladoras e um diálogo na construção de melhores resultados regulatórios. Revista Eletrônica do Mestrado em Direito da UFAL, v. 5, n. 1, p. 183-223, 2014.

REZENDE, G. P.; NAKAO, S. H. Gerenciamento de resultados e a relação com o lucro tributável das empresas brasileiras de capital aberto. Revista Universo Contábil, v. 8, n. 1, p. 06-21, 2012.

ROSSETTI, J. P.; ANDRADE, A. Governança corporativa: fundamentos, desenvolvimento e tendências. 7. ed. São Paulo: Atlas, 2014.

SAN MARTIN REYNA, J. M. Interacción entre mecanismos internos y externos de gobierno como elemento detonante de la creación de valor: un estudio internacional. Revista

Brasileira de Gestão de Negócios, v. 14, n. 43, p. 143-158, 2012.

SCHIPPER, K. Commentary on earnings management. Accounting Horizon, v. 3, p. 91-102, 1989.

SEIDLER, J. C. O. Índice de earnings quality das empresas listadas no mercado de capitais no Brasil. 2015. 93 f. Dissertação (Programa de Pós-Graduação em Ciências Contábeis) - Universidade do Vale do Rio dos Sinos, São Leopoldo, 2015.

SILVA, A.; PLETSCH, C. S.; VARGAS, A. J.; FASOLIN, L. B.; KLANN, R. C. Influência da auditoria sobre o gerenciamento de resultados. Revista de Contabilidade do Mestrado em Ciências Contábeis da UERJ, v. 19, n. 3, p. 59-69, 2014.

SILVA, E. C. Governança corporativa nas empresas: guia prático de orientação para acionistas e conselho de administração. São Paulo: Atlas, 2006.

SILVA, J. O.; BEZERRA, F. A. Análise do gerenciamento de resultados e o rodízio de firmas de auditoria nas empresas de capital aberto. Revista Brasileira de Gestão de Negócios, v. 12, n. 36, p. 304, 2010. 
SILVA, K. L.; OLIVEIRA, M. C.; DE LUCA, M. M. M; ARAÚJO, O. C. A Implementação dos controles internos e do comitê de auditoria segundo a lei SOX: o caso

Petrobras. Contabilidade Vista \& Revista, v. 20, n. 3, p. 39-63, 2009.

SILVA, M. S.; GALDI, F. C.; TEIXEIRA, A. M. C. Estudo sobre o efeito das eleições presidenciais no gerenciamento de resultados de empresas atuantes em setores regulados. Contabilidade Vista \& Revista, v. 21, n. 2, p. 45-68, 2010.

SILVEIRA, A. D. M.; BARROS, L. A. B. C. Determinantes da qualidade da governança corporativa das companhias abertas brasileiras. Revista Eletrônica de Administração, v. 14, n. 3, p. 1-29, 2008.

SILVEIRA, A. D. M.; BARROS, L. A. B. de C.; FAMÁ, R. Estrutura de governança e desempenho financeiro nas companhias abertas brasileiras: um estudo empírico. Caderno de Pesquisas em Administração, v. 10, n. 1, jan./mar. 2003.

SORRENTINO, M. S. A. S.; TEIXEIRA, B.; VICENTE, E. F. R. Comitê de auditoria: adequação às regras da SOX, Bacen, Susep e IBGC. Revista de Educação e Pesquisa em Contabilidade (REPeC), v. 10, n. 3, 2016.

SUN, J; LAN, G; LIU, G. Independent audit committee characteristics and real earnings management. Managerial Auditing Journal, v. 29, n. 2, p. 153-172, 2014.

TEIXEIRA, B.; CAMARGO, R. V. W.; VICENTE, E. F. R. Relação entre as características do comitê de auditoria e a qualidade da auditoria independente. Revista Catarinense da Ciência Contábil (CRCSC), v. 15, n. 44, p. 60-74, 2016.

THIRUVADI, S.; HUANG, H. W. Audit committee gender differences and earnings management. Gender in Management: An International Journal, v. 26, n. 7, p. 483-498, 2011.

VAN DER WALT, N.; INGLEY, C.; SHERGILL, G. S.; TOWNSEND, A. Board configuration: are diverse boards better boards?. Corporate Governance: The international Journal of Business in Society, v. 6, n. 2, p. 129-147, 2006.

XIE, B.; DAVIDSON III, W. N.; DADALT, P. J. Earnings management and corporate governance: the role of the board and the audit committee. Journal of Corporate Finance, v. 9 , n. 3, p. 295-316, 2003.

YANG, J. S.; KRISHNAN, J. Audit committees and quarterly earnings management. International Journal of Auditing, v. 9, n. 3, p. 201-219, 2005. 